DIVISION OF THE HUMANITIES AND SOCIAL SCIENCES

CALIFORNIA INSTITUTE OF TECHNOLOGY

PASADENA, CALIFORNIA 91125

POLITICAL COMPETITION IN A MODEL OF ECONOMIC GROWTH:

SOME THEORETICAL RESULTS

Richard Boylan

Washington University in St. Louis

John Ledyard

California Institute of Technology

Richard D. Mckelvey

California Institute of Technology

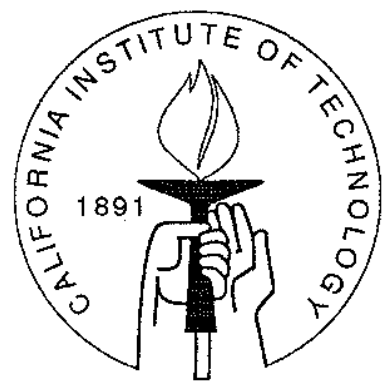

SOCIAL SCIENCE WORKING PAPER 780

October 1991

Revised December 1992 


\title{
POLITICAL COMPETITION IN A MODEL OF ECONOMIC GROWTH: SOME THEORETICAL RESULTS ${ }^{1}$
}

\begin{abstract}
We study a one-sector model of economic growth in which decisions about capital accumulation and consumption are made through a political process of two candidate competition. Each voter's utility for a consumption stream is the discounted value of that voter's utility of consumption in each period. We consider the case when voters' one period utility functions for consumption are identical but discount factors are different. We are particularly interested in the conditions under which neoclassical optimal growth paths occur, and conditions in which political business cycles occur. The answer depends on the ability or inability of the candidates to commit to multi-period investment strategies.

If candidates can commit indefinitely into the future, then a political (majority rule) equilibrium path will not exist if all discount factors are different. For any feasible consumption path, there is a perturbation which is majority preferred to it. For any neoclassical optimal path there exists a perturbated path that is preferred to it either unanimously or by all but one voter. These results are true even if the perturbations can differ at no more than three consecutive periods from the original path.

If candidates are unable to commit to multi-period plans, we show there is a unique subgame perfect, stationary, symmetric equilibrium to the infinite horizon two candidate competition game; namely the optimal consumption path for the median voter. The equilibrium is unique in the following sense: It is the unique limit of subgame perfect equilibria to the finite horizon electoral game.

In the case when candidates can commit for a finite time into the future, we show that a stationary minmax path (a path which minimizes the maximum vote that can be obtained against it) yields a political business cycle.
\end{abstract}

\footnotetext{
${ }^{1}$ Support for this research was provided, in part by NSF grant \#SES-8604348 to the California Institute of Technology. We are grateful to a referee for pointing out that our results could be extended to supra majority rules, as in Proposition 2.
} 


\title{
POLITICAL COMPETITION IN A MODEL OF ECONOMIC GROWTH:
}

\author{
SOME THEORETICAL RESULTS
}

\author{
Richard Boylan, John Ledyard, and Richard D. McKelvey
}

\section{INTRODUCTION}

In this paper, we study the consumption-investment paths generated by a competitive political process operating in the temporal environment of a one-sector growth model. We are particularly interested in the conditions which lead to neoclassical optimal paths, and those which lead to political business cycles in such a political-economic system.

There is a long history of work in the economics literature on the problem of economic growth. The problem was originally formulated by Ramsey [1928], was taken up again by Solow [1956], and considered from the point of view of optimal economic policy by Cass [1965], Koopmans [1965] and others.

While the problem of economic growth has received a lot of attention, very little has been done to incorporate political institutions into such models. One exception is the work of Beck [1978], who studied political behavior in a continuous time, one-sector model of economic growth, where voters differ only in their time preferences. Beck shows that if the set of feasible plans is limited to consumption paths that are optimal for at least one voter, then the path that is optimal for the voter with the median discount factor is a majority core. He conjectures that the median voter path is no longer a majority core if all plans are feasible. He also argues that the plan for the median voter is a "local equilibrium", in which no majority can agree on an instantaneous deviation, assuming that the optimal path for the median voter will be followed after that instant.

When one leaves the setting of growth theory, there is a fair amount of work that 
has attempted to characterize the type of fiscal and monetary policy that would be generated by political processes. A recurrent theme in this literature is that if politicians are allowed to make economic decisions, they will generate "political business cycles" - business cycles coinciding with the term of office of the politicians. Nordhaus [1975] first derived such results in a model in which the incumbent office holder must choose among different points along a Phillips curve. He also presented some empirical evidence supporting the existence of political business cycles in some countries. $^{2}$ Nordhaus's theoretical argument depends crucially on voter myopia. Subsequent papers by Rogoff [1990] (see also Rogoff and Sibert [1988]) and Alesina [1987] have derived political business cycles without having to assume voter myopia. Rogoff and Rogoff and Sibert show that the introduction of asymmetric information over the competency of political candidates can generate a political business cycle. In this model a business cycle emerges as a signalling equilibrium in which the size of the cycle is used, by the candidate, to signal its competency to the voters. Alesina assumes that different political parties have different relative preferences over the trade-off between inflation and unemployment levels. He then gets political business cycles emerging even when voters have rational expectations, due to the fact that the election provides a random shock. Both of the above models are partial equilibrium models. Rogoff's economy does not have the capability of real growth, while Alesina's political parties have exogenously given policy positions.

In this paper, we study a discrete-time version of Beck's model: we consider a one sector growth model in which voters differ only in their time preferences, and in which they vote over the optimal plan. We consider the case where all plans, rather than just plans that are optimal for one voter, are available.

We begin, in section 2 , by introducing the details of the standard one-sector growth model and providing some background on optimal investment-consumption paths for those not familiar with this framework. We then formulate the political growth model as a game of two-candidate competition over the set of feasible consumption-investment paths. The variable which we focus on is the length of time

\footnotetext{
${ }^{2}$ Subsequent empirical evidence for cycles is mixed. McCallum (1978) and Golden-Poterba (1980) do not find evidence of business cycles in the U. S. . But other studies find evidence of cycles in other countries. Empirical evidence for cycles can be found in Allen, Sulock and Sabo [1986], Cargill and Hutchinson [1991], Davidson, Fratianni and von Hagen [1990], Findlay [1990], Keil[1988], Paldam [1979] and Soh [1986].
} 
for which political candidates can commit themselves. The type of investmentconsumption path generated is critically dependent upon whether or not the candidates are able to commit to multi-period investment plans in a credible manner.

In section 3, we consider what paths are chosen if candidates can credibly commit and voters can choose between investment-consumption paths to be followed indefinitely into the future. If all voters have different discount factors, we prove Beck's conjecture that the median voter path is not a core when plans that are not optimal for some voter are available. We actually prove a stronger result - that there is no majority rule core if non optimal plans are feasible, and that any neoclassical optimal path (a path that could be optimal for a voter with time consistent preferences) can be defeated almost unanimously.

In section 4, we consider what consumption paths are chosen if it is impossible for candidates to credibly commit to indefinitely long consumption plans, but can instead just commit for one period. We show that there is a "unique" subgame perfect, stationary, symmetric equilibrium to the two-candidate competition that supports the consumption path that is optimal for the voter with median discount rate. The equilibrium we identify is "unique" in the following sense. It is the limit of unique subgame perfect equilibria to the finite horizon electoral game, and any equilibrium to the infinitely repeated game that is such a limit must yield the same consumption investment path. In essence, we show that Beck's intuition is correct in the discrete time setting.

In section 5, we consider the case where candidates can commit for only a finite time into the future. We investigate which paths can be defeated by the smallest majorities. We show that a stationary minmax path (a path that can be defeated by the smallest majority) exibits a political business cycle.

We conclude that political business cycles can be explained by models that require no myopia or incomplete information, and that the existence and severity of political business cycles may be related to the length of the time horizon that the political system can commmit. ${ }^{3}$ Our analysis also raises questions as to whether

${ }^{3}$ In connection with this result, the findings of Paldam (1979) are quite intriguing. He studies 49 stable governments in 17 OECD countries, finding significant business cycles in four year governments, but no significant cycles in three year governments. Thus longer terms in office lead to less stable consumption paths. 
neoclassical optimal paths are socially desirable, since they can always be defeated by virtually unanimous majorities. In particular, cyclical paths are majority preferred to them and can only be defeated by smaller majorities.

\section{THE POLITICAL-ECONOMIC GROWTH MODEL}

We choose the simplest possible dynamic framework to model the economy: a one sector growth model. We also choose the simplest possible political process: twocandidate competition. The economy is very simple: there is one good which can be consumed or invested (for example corn which can be planted or eaten). Decisions on the consumption-investment stream are made by the political process.

We first review the basic setup and results of the one sector growth model we use: Let $F: \mathbb{R} \rightarrow \mathbb{R}$ be a twice continuously differentiable concave production function ${ }^{4}$ with $F(0)=0, F^{\prime}(0)=+\infty, F^{\prime}(\infty)=0$. Let $k_{t}$ be the per capita capital stock at the beginning of date $t$, and $c_{t}$ be the consumption per capita on date $t$, and let $T \in \mathbb{N} \cup\{\infty\}$. The technology can be summarized in the fundamental equation of growth theory: we are given $\bar{k}>0$, and for $t=0,1, \mathscr{Q}, \ldots, T$,

$$
c_{t}+k_{t+1}=F\left(k_{t}\right)
$$

where

$$
k_{0}=\bar{k}, k_{t} \geq 0, c_{t} \geq 0
$$

Thus each period, the output of production is divided between consumption and capital for use in next period production. Any path $c=\left\{c_{t}\right\}_{0<t<T}$ which is a feasible solution to (2.1) and (2.2) is called a feasible consumption path. Let $\mathcal{C}$ denote the set of feasible consumption paths.

The one sector growth model has been studied extensively in the case where a particular social welfare function is defined. The primary interest has been in solving for a feasible consumption investment path which maximizes the welfare function. In most cases the welfare function has been assumed to be temporally separable with impatience represented by a discount factor, $\delta$. That is, for any $c \in \mathcal{C}, U(\boldsymbol{c})=$ $\sum_{t=0}^{T} \delta^{t} u\left(c_{t}\right)$, where $\delta \in(0,1)$ and $u: \mathbb{R}_{+} \rightarrow \mathbb{R}$ satisfies $u^{\prime}(c)>0, u^{\prime}(0)=\infty$ and $u^{\prime \prime}(c)<0$

${ }^{4}$ The production function $F(k)$ is frequently assumed to be of the form $f(k)=f(k)+(1-\lambda) k$, where $\lambda$ is the depreciation rate of capital stock, and $f(k)$ is the net output. Hence, $(1-\lambda) k$ is the undepreciated capital. 
for all $c \in \mathbb{R}_{+}$. The problem to be solved is:

$$
\max _{c \in \mathcal{C}} \sum_{t=0^{\delta}}^{T} u\left(c_{t}\right)
$$

Any solution to the above problem (for some $\delta$ ) will be called a neoclassical optimal path.

Any solution $\left\{\left(c_{t}^{*}, k_{t}^{*}\right)\right\}_{0<t<T}$ can be characterized by a family of policy functions $h_{t}(k ; T)$ and $g_{t}(k ; T)=F(k)-h_{t}(k ; T)$ for the optimal capital and consumption at time $t$, as a function of capital at the previous time period, such that $k_{0}^{*}=\bar{k}$, $k_{t+1}^{*}=h_{t}\left(k_{t}^{*}, T\right)$, and $c_{t}^{*}=g_{t}\left(k_{t}^{*}, T\right)$. For the infinite horizon model, the solution can be expressed in terms of a single pair of functions $h(k)=h_{t}(k ; \infty)$ and $g(k)=g_{t}(k ; \infty)$. Further, $h$ satisfies $h^{\prime}>0$ and $h(k)<k^{*}$ for $k<k^{*}$, and $h(k)>k^{*}$ for $k>k^{*}$, where $k^{*}$ is defined by ${ }^{5}$

$$
F^{\prime}\left(k^{*}\right)=\frac{1}{\delta}
$$

The above results imply that the optimal path of capital begins at $k_{0}$ and converges monotonically to $k^{*}$. Similarly, the optimal path of consumption converges monotonically to $c^{*}=F\left(k^{*}\right)-k^{*}$.

In this paper, instead of using a social welfare function, we assume that there is a set $N$ of $n$ voters. Voters all have the same one period utility for consumption, but differ in their time preferences. Voter $i \in N$, has a discount factor $0<\delta_{i}<1$, and this voter's utility function $U_{i}: \mathcal{C} \rightarrow \mathbb{R}$ over consumption paths is given by ${ }^{6}$

$$
U_{i}(\boldsymbol{c})=\sum_{t=0}^{T} \delta_{i}^{t} u\left(c_{t}\right)
$$

where $u: \mathbb{R}_{+} \rightarrow \mathbb{R}$ satisfies $u^{\prime}(c)>0, u^{\prime}(0)=\infty$ and $u^{\prime \prime}(c)<0$ for all $c \in \mathbb{R}_{+}$. We will assume throughout that any two distinct voters have distinct discount factors: $i$. e.,

\footnotetext{
${ }^{5}$ To see this, let $v^{*}$ be a function satisfying $v^{*}(k)=\max _{c}\left[u(c)+\delta v^{*}(F(k)-c)\right]=\max _{h}$ $\left[u(F(k)-h)+\delta v^{*}(h)\right]$. Then $v^{*}(k)=u(F(k)-h(k))+\delta v^{*}(h(k))$, where for all $k, h(k)$ satisfies $\partial v^{*} / \partial h=0 \Rightarrow u^{\prime}(F(k)-h(k))=\delta v^{* \prime}(h(k))$. By the Envelope theorem, $v^{*^{\prime}}(k)=\partial v^{*} / \partial k=u^{\prime}(F(k)-$ $h(k)) F^{\prime}(k)$. Hence, $\quad u^{\prime}(F(k)-h(k))=\delta v^{* \prime}(h(k))=\delta u^{\prime}(F(h(k))-h(h(k))) F^{\prime}(h(k)) \Rightarrow u^{\prime}(g(k))=$ $\delta u^{\prime}(g(h(k))) F^{\prime}(h(k))$. Note that if $h(k)=k$, then $\delta u^{\prime}(g(k))=u^{\prime}(g(k)) / F^{\prime}(k) \Rightarrow F^{\prime}(k)=1 / \delta$. The value function, $v^{*}$ is continuous, differentiable, strictly increasing, and strictly concave. In other words, $v^{* \prime}(k)>0$, and $v^{* \prime \prime}(k)<0$. For more details the reader can consult Harris [1987].

${ }^{6}$ One might worry about the distribution of $c_{4}$ across voters, but we will treat this as a public good. That is, the elected candidate will pick $c_{t}$, the amount of $y_{t}$ to be consumed, yielding voter $i$ a utility level of $u\left(c_{t}\right)$ for that period. Most of the results we show in this paper extend to the case where the good is private with one period utility functions being logarithmic (see Boylan [1992]).
} 
$i \neq j \Rightarrow \delta_{i} \neq \delta_{j}$.

In addition to the voters, we assume there are two candidates. The political process consists of a sequence of elections, in each of which the two candidates compete for office by offering consumption plans for the duration of their term of office. We assume that at period $i L$, the society is able to choose a policy that commits them for the next $L$ periods (or $T-i L$ periods if this is less than $L$ ). Thus, there are $\mathcal{T}$ elections, in each of which one of two candidates is elected to serve a term of office of length $L$ periods, where $1 \leq \mathcal{T} L \leq T$.

The above represents a general framework for study of the problem of growth under two candidate competition. In this paper we will consider some special cases of the above model. In the first case, considered in section 3 there is only one election with a very long term of office: $\sigma=1, L=T=\infty$. In the second case, considered in section 4 , we consider the case when commitment is not possible: $\mathcal{T}=T=\infty, L=1$. In the final case, considered in section 5 , there is an infinite sequence of elections with finite terms of office: $\mathcal{T}=T=\infty, L>1$.

These three cases represent extremes in the ability to commit or plan for the future. In the first case, the political process makes a decision once and for all as to the plan to be followed into the future. The plan of the elected candidate is carried out with no possibility for revision later on. In the second case, the political process allows only incremental planning, with decisions on current consumption made at that point in time, and no ability to commit for the future. The final case corresponds to the situation in which there are periodic elections, in which candidates make promises for the policy that they will follow during their term of office, and these promises are believed by the voters and carried out by the candidates once in office.

\section{INDEFINITE COMMITMENT}

Suppose that candidates and voters can commit to carry out multi-period actions for significant periods into the future. What will a majority rule equilibrium look like? The answer, of course, depends on the types of commitments that are possible and credible. In this section, we will make about as extreme an assumption as is possible. We assume candidates can commit to feasible consumption paths, for all $t$, and that voters and the other candidate believe these commitments. We assume that there is 
one election, at time $\tau=0$ to determine the consumption path to be followed into the future. The two candidates offer proposals, and the voters vote for the plan that they like the best. We assume that candidates get utility just from winning the election, and have no policy preferences. Voters get the utility of the consumption stream offered by the winning candidate.

Formally, we assume that there is a set $K=\{1,2\}$ of two candidates, and that the strategy set for candidate $i \in K$ is $S_{i}=\mathfrak{C}$, the set of feasible consumption paths. Given a pair of strategies adopted by the candidates, we assume that voters vote for the candidate proposing the policy they like best (abstaining if indifferent). Write $n\left(\boldsymbol{c}, \boldsymbol{c}^{\prime}\right)=\left|\left\{i \in N: U_{i}(\boldsymbol{c})>U_{i}\left(\boldsymbol{c}^{\prime}\right)\right\}\right|$ to be the vote of $\boldsymbol{c}^{\prime}$ against $\boldsymbol{c}$. Then for any $s=\left(s_{1}, s_{2}\right) \in \mathfrak{C} \times \mathfrak{C}$, we can define the payoff function $M(s)=M_{1}(s)=-M_{2}(s)$ for a two person zero sum game between the candidates by:

$$
M_{j}(s)=\left\{\begin{array}{rlr}
1 & \text { if } & n\left(s_{1}, s_{2}\right)>n\left(s_{2}, s_{1}\right) \\
-1 & \text { if } & n\left(s_{1}, s_{2}\right)>n\left(s_{2}, s_{1}\right) \\
0 & \text { otherwise }
\end{array}\right.
$$

The above situation corresponds to a standard game of two candidate electoral competition under majority rule, where the space from which the candidates choose their policies is the set $C$. We want to identify pure stratgy Nash equilibria to this game.

A point $c \in \mathcal{C}$ is a majority rule core if there is no other feasible path, $\boldsymbol{c}^{\prime} \in \mathcal{C}$ such that $n\left(\boldsymbol{c}, \boldsymbol{c}^{\prime}\right)>n / 2$. Given the assumptions we have made, $(\boldsymbol{c}, \boldsymbol{c})$ is a Nash equilibrium to (3.1) if and only if $c$ is a majority core (See proof to Proposition 1 in the appendix). Our main finding in this section (proven in the appendix) is that there will be no pure strategy Nash equilibria to the game (3.1).

PROPOSITION 1: If all voters have different discount factors, there is no pure strategy Nash equilibrium for (3.1). Equivalently, there is no majority core in $C$.

The above result may seem surprising at first glance. One might think (at least we did) that when utility functions differ only by one parameter, that the median voter theorem 
would apply, implying that the optimal path for the voter with the median discount factor would be a majority core point. To illustrate that this intuition is wrong, we give an example showing how the optimal path for the median voter can be defeated.

EXAMPLE 1: Assume $u(c)=\ln (c), F(k)=k^{1 / 2}$. There are three voters with $\delta_{1}=.5$, $\delta_{2}=.05$, and $\delta_{3}=.95$. Let $c^{*}$ and $k^{*}$ be the steady state values of consumption and capital on the optimal path for the voter with the median discount factor, namely voter 1. By equation (2.4), $k^{*}=.0625$, and $c^{*}=F\left(k^{*}\right)-k^{*}=.1875$. For simplicity, we assume initial capital is at the steady state, $k^{*}$, so that the optimal path is $c^{*}=\left(c^{*}, c^{*}\right.$, $\left.c^{*}, \ldots\right)$. Now consider the path $c^{\prime}=\left(c_{0}, c_{1}, c_{2}, c^{*}, c^{*}, c^{*}, \ldots\right)$, with $c_{0}=.1914$, $c_{1}=.17188$, and $c_{2}=.20243$. It is easily checked that this path is feasible. Further, both voters 2 and 3 prefer $c^{\prime}$ to $c^{*}: U_{2}\left(c^{\prime}\right)=-1.745+\delta_{2}^{3} U_{2}\left(c^{*}\right)>-1.762+$ $\delta_{2}^{3} U_{2}\left(c^{*}\right)=U_{2}\left(c^{*}\right)$, and $U_{3}\left(c^{\prime}\right)=-4.768+\delta_{3}^{3} U_{3}\left(c^{*}\right)>-4.775+\delta_{3}^{3} U_{3}\left(c^{*}\right)=U_{3}\left(c^{*}\right)$.

The intuition for the example is as follows. The optimal path for the median voter is beaten by selecting three successive periods, and then perturbing the path a small distance in the direction $z=\left(\delta_{1}^{2},-2 \delta_{1}, 1\right)=(1 / 4,-1,1)$. This direction vector is normal to gradient for the median voter, and since $c^{*}$ is optimal for voter $1, z$ is also in the tangent space of the constraint. Further, $z$ has positive inner product with the gradient vectors of all other voters. It follows that a small change in the direction $z$ will improve the utility of all voters but voter 1 , and be approximately feasible. The perturbation must be adjusted slightly to maintain feasibility, (which we do by just perturbing $c_{0}$ and $c_{1}$, and then setting $c_{2}=F\left(F\left(F\left(k^{*}\right)-c_{0}\right)-c_{1}\right)-k^{*}$.) This perturbation results in slightly more consumption in the first period, followed by a large drop in consumption in the second period, and a large rise in consumption in the last period. The consumption drop in the second period is necessary to allow investment in order to finance the third period rise in consumption. This proposed change is able to attract voters with lower discount factors because of the greater consumption right away. But it is simultaneously able to attract voters with higher discount factors because of the higher total consumption, which voters with higher discount factors are willing to wait for. 
The above example is worked out for an optimal path of the median voter. However, Proposition 1 establishes that any path, optimal or not, can be defeated by another path. Hence, the above result does not allow us to make any specific prediction about what kinds of paths might be observed.

Given the results of Proposition 1 the next natural question is to ask is if there are any paths that are "more stable" than others. To address this question, we consider the size of the majority by which various paths can be defeated, and attempt to identify those that can be defeated by the smallest majority.

PROPOSITION 2: If all voters have different discount factors, then for any neoclassical optimal path, $c \in \mathfrak{C}$, there is an alternative path $\boldsymbol{c}^{\prime} \in \mathfrak{C}$, which defeats $\boldsymbol{c}$ by at least $n-1$ votes. If $c$ is not optimal for any voter $i$, then it can be defeated by $n$ votes. The same results hold if we restrict the set of alternative paths to those that differ from $c$ at no more than 3 consecutive periods.

\section{ONE PERIOD COMMITMENT}

We showed that if voters can choose between multi period proposals, no equilibrium exists. However, it can be argued that multiple period proposals are not credible. Because of the temporal nature of the decision, period $t$ decisions must be implemented before period $t+1$ decisions. But once period $t$ decisions are implemented, there is always the opportunity to revise the period $t+1$ decisions. In making the period $t$ decision, all players would realize this aspect of the problem, and they would make the period $t$ decision conditional on the belief that the period $t+1$ decision will be made subject to preferences at that point in time. This means that multi-period deviations from a proposed "status quo" consumption path can only occur if players will want to continue with the deviation even in the later periods of the deviation. For example, if a coalition supporting a deviation contains members with both high and low discount factors, then for the deviation to benefit both groups, it may be necessary that the groups get their benefits at different times. Once the players with low discount factors have received their benefits from higher initial levels of consumption, they may no longer be willing to support the investment necessary to help 
their coalition partners with higher discount factors. Of course, if the coalition members had realized this problem when they were contemplating the proposed change, they would never have formed the coalition in the first place. This realization by the individuals that coalition members may want to back out of their agreements later in the process will make it harder to find proposals which can beat the status quo.

In this section we make the other extreme assumption about the possibilities for credible commitments and assume that no commitment is possible. We do this by requiring behavior to be subgame perfect; that is, an equilibrium strategy must be equilibrium behavior at every period. We ask whether there are any feasible consumption paths which are political equilibria under the restriction that any proposed change must be supported by subgame perfect behavior. We need first to be more precise about strategies and equilibrium.

We first look at the finite horizon model. In the finite horizon model, we show that there is a unique equilibrium for any finite horizon, $T$, namely the optimal path for the voter with the median discount factor. We then show that as $T$ goes to infinity, the solution to the finite horizon model converges to the stationary solution of the infinite horizon model, namely to the optimal path in the infinite horizon model for the voter with median discount factor.

Defining strategies requires quite a bit of notation because we are dealing with a repeated game in which as the capital stock changes, so does the strategy space and the payoff function for the voters. Further, we make very weak assumptions on what information individuals have, so that our model can include various secnarios. For instance, some voters may be more informed than others.

A history includes an initial capital stock, and for each period the proposals of each candidate, the vote of each individual, and the outcome of the tie breaking procedure. Write $H_{t}=\mathbb{R} \times\left(\mathbb{R}^{2} \times(\mathrm{K} \cup\{0\})^{n} \times K\right)^{t-1}$ for the set of all histories at time $t$. Let $k^{t}: H_{t} \rightarrow R$ be such that if the history at time $t$ is $h_{t} \in H_{t}$, then the capital endowment at time $t$ is $k^{t}\left(h_{t}\right)$. Notice that $k^{0}\left(h_{0}\right)=h_{0} \equiv k$. Let $r_{t}^{i} \subset 2^{H_{t}}$ be the information partition which describes the information of individual $i$ at time $t$. We assume that the partition is such that individual $i$ knows $k_{t}$; first note $\mathfrak{H}_{t}^{i}$ is finer than $\mathfrak{H}_{t}$, where $\mathfrak{H}_{t}=\left\{\left(h^{t}\right)^{-1}(k): k \in k^{t}\left(H_{t}\right)\right\}$. 
Voter $i$ 's strategy at time $t$ is a function $\sigma_{t}^{i}: H_{t} \times \mathbb{R}^{2} \rightarrow K \cup\{0\}$ such that for all candidates' promises $\left(c^{1}, c^{2}\right), \quad \sigma_{t}^{i}: H_{t} \times\left(c^{1}, c^{2}\right) \rightarrow K \cup\{0\}$ is $\mathcal{H}_{t}^{i}$-measurable. If $\sigma_{t}^{i}(h, c)=j$, then voter $i$, given a history of $h$ and promises $c$, votes for candidate $j$. If $\sigma_{t}^{i}(h, c)=0$, then voter $i$ abstains. Voter $i$ 's strategy is a sequence $\sigma^{i}=\left(\sigma_{t}^{i}\right)_{t=0}^{T}$.

Candidate $j$ 's strategy at time $t$ is a $\mathfrak{F}_{t}^{j}$-measurable function $s_{j}^{t}: H_{t} \rightarrow \mathbb{R}$ such that for all $h \in H_{t}, s_{t}^{j}(h) \in\left[0, F\left(k_{t}(h)\right)\right]$. If $s_{t}^{j}(h)=c^{j}$, then candidate $j$, given history $h$, promises consumption $c^{j}$. All promises must be feasible. Candidate $j$ 's strategy is a sequence $s^{j}=\left(s_{t}^{j}\right)_{t=0}^{\infty}$. Let $\sigma=\left(\sigma^{1}, \ldots, \sigma^{n}\right)$ be a profile of strategies for the voters, and let $s=\left(s^{1}, s^{2}\right)$ be a profile of strategies of the candidates. We write $e=(s, \sigma)$ for a $(n+2)$-tuple of strategies by the voters and candidates, respectively. For any strategy $n$-tuple $\sigma_{t}$ by the voters, candidate promises $c=\left(c^{1}, c^{2}\right) \in \mathbb{R}_{+}^{2}$, capital stock $k$, and candidate $j \in K$, define

$$
\Phi_{t}^{j}\left(h_{t}, c, \sigma\right)=\left|\left\{i \in N: \sigma_{t}^{i}\left(h_{t}, c\right)=j\right\}\right|-\left|\left\{i \in N: \sigma_{t}^{i}\left(h_{t}, c\right) \in K-\{j\}\right\}\right|
$$

to be the plurality for candidate $j$ at time $t$. For any time $t$, history $h_{t}$, strategy $(n+2)$ tuple $e=(s, \sigma)$, and $x \in K$, the winning candidate is

$$
w_{t}\left(h_{t}, e, x\right)= \begin{cases}\underset{j}{\arg \max _{j} \Phi_{t}^{j}\left(h_{t}, s_{t}\left(h_{t}\right), \sigma\right)} & \text { if } \max _{j} \Phi_{t}^{j}\left(h_{t}, \mathrm{~s}_{t}\left(h_{t}\right), \sigma\right)>0 \\ x & \text { otherwise. }\end{cases}
$$

Thus, $w_{t}\left(h_{t}, e, x\right)$ indicates the winning candidate at time $t$ if the history stock is $h_{t}$, candidates adopt the strategies $s^{j}$, voters adopt the strategies $\sigma^{i}$, and ties are broken in favor of candidate $x$. Every strategy $e$, capital stock $k$, and vector $x=\left(x_{0}, x_{1}, x_{2}, \ldots\right.$, $\left.x_{T}\right) \in K^{T}$ determines a sequence of winning candidates, $\left\{\left(w_{t}\left(h_{t}, e, x\right)\right\}_{0}<t<T\right.$.

Suppose at time $t$ the history is $h \in H_{t-1}$, the strategy is $e$, and the tie break is $x$. Then, after period $t+1$, the history will be

$$
\begin{gathered}
h_{\tau+1}^{t}(h, e, x)=\left(h_{\tau}^{t}(h, e), s_{t+\tau+1}^{1}\left(h_{\tau}^{t}(h, e), e\right), s_{t+\tau+1}^{2}\left(h_{\tau}^{t}(h, e), e\right),\right. \\
\left.\sigma_{t+\tau+1}^{1}\left(h_{\tau}^{t}(h, e), e\right) \ldots, \sigma_{t+\tau+1}^{n}\left(h_{\tau}^{t}(h, e), e\right), x_{t+\tau+1}\right),
\end{gathered}
$$

where $h_{0}^{t}(h, e, x)=h$. Let

$$
c_{t}\left(h_{t}, e, x\right)=s_{t}{ }^{w_{t}\left(h_{t}, e, x\right)}\left(h_{t}\right)
$$


be the consumption selected by the winning candidate. Let

$$
V_{t}^{i}(h, e, x)=\sum_{\tau=0}^{T-t} \delta_{i}^{\tau} u_{i}\left(c^{i}{ }_{t+\tau}\left(h_{t+\tau}^{t}(h, e, x), e, x\right)\right)
$$

Thus, $V_{t}^{i}(h, e, x)$ represents the payoff to voter $i \in N$ in period $t$, given strategies $e$, history $h$, and tie breaking procedure $\boldsymbol{x}$.

For each $t, x_{t}$ is a random variable which is 1 with probability $\frac{1}{2}$, and 2 with probability $\frac{1}{2}$. Let $G(x)$ denote the joint distribution of $x$.

Note that

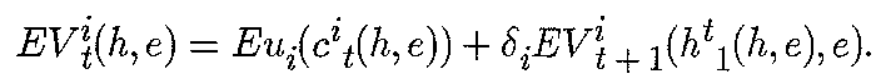

Also, for any $t^{t h}$ period consumption, $c_{t} \in \mathbb{R}_{+}$, let

$$
E V_{t}^{i}\left(h, e ; c_{t}\right)=u_{i}\left(c_{t}\right)+\delta_{i} E V_{t+1}^{i}\left(\left(h, c_{t}, \sigma_{t}^{1}(h, c), \ldots, \sigma_{t}^{n}(h, c)\right), e\right) .
$$

This represents the value, to voter $i$, of a one period deviation, in which $c_{t}$ is chosen in the period $t$, and then all players revert to $e$ in periods $t+1, t+2, \ldots$.

Next, for any time $t$, capital stock $k$, strategy $n+2$ tuple $e$, and $j \in K$, define

$$
\rho_{t}^{j}\left(h_{t}, e\right)= \begin{cases}1 & \text { if } \Phi_{t}^{j}\left(h_{t}, s\left(h_{t}\right), \sigma\right)>0 \\ 0 & \text { if } \Phi_{t}^{j}\left(h_{t}, s\left(h_{t}\right), \sigma\right)<0 \\ \frac{1}{2} & \text { if } \Phi_{t}^{j}\left(h_{t}, s\left(h_{t}\right), \sigma\right)=0\end{cases}
$$

So $\boldsymbol{\rho}_{t}^{0}\left(h_{t}, e\right)$ is the probability that candidate $j$ wins. For any history $h$, strategy $n+2$ tuple $e$, and $x$, define

$$
W_{t}^{j}(h, e, x)=\sum_{\tau=0}^{T-t} \delta_{j}^{\tau} \rho_{j}^{\tau}\left(h_{\tau}^{t}(h, e, x), e\right)
$$

to be the expected payoff for candidate $j$.

Also, as before, we can define, for any $t=1, \ldots, T, j \in K$, and $c^{j} \in \mathbb{R}_{+}$,

$$
\begin{aligned}
& \operatorname{EW}_{t}^{j}\left(h, e ; c^{j}\right)=1+\delta_{j} E W_{t}^{j}\left(\left(h, c^{j}, s^{-j}(h), \sigma^{1}\left(h, c^{j}, s^{j}(h)\right), \ldots, \sigma^{n}\left(h, c^{j}, s^{j}(h)\right)\right), e, x\right) \\
& \text { if } \Phi_{t}^{j}\left(h,\left(c^{j}, s^{-j}(k)\right), \sigma\right)>0
\end{aligned}
$$




$$
\begin{aligned}
&=\delta_{j} E W_{t}^{j}\left(\left(h, c^{j}, s^{-j}(h), \sigma^{1}\left(h, c^{j}, s^{j}(h)\right), \ldots, \sigma^{n}\left(h, c^{j}, s^{j}(h)\right)\right), e, x\right) \\
& \text { if } \Phi_{t}^{j}\left(h,\left(c^{j}, s^{-j}(k)\right), \sigma\right)<0 \\
&=\frac{1}{2}+\delta_{j} E W_{t}^{j}\left(\left(h, c^{j}, s^{-j}(h), \sigma^{1}\left(h, c^{j}, s^{j}(h)\right), \ldots, \sigma^{n}\left(h, c^{j}, s^{j}(h)\right)\right), e, x\right) \\
& \text { if } \Phi_{t}^{j}\left(h,\left(c^{j}, s^{-j}(k)\right), \sigma\right)=0
\end{aligned}
$$

This represents the expected payoff to candidate $j$, if the capital stock were $k$, and candidate $j$ were to unilaterally vary its strategy at time $t$ using $c^{j}$, and then all players revert to $e$.

DEFINITION: A strategy $e^{*}=\left(s^{*}, \sigma^{*}\right)$ is a growth equilibrium if, for all $t$,

a. For the voters: For all $i \in N, h \in H_{t}$, and $c=\left(c^{1}, c^{2}\right) \in \mathbb{R}^{2}+$

$$
\begin{aligned}
& \sigma_{t}^{i *}(h, c)=\arg \max _{j \in K} E V_{t}^{i}\left(h, e^{*} ; c^{\jmath}\right) \quad \text { if } E V_{t}^{i}\left(h, e^{*} ; c^{j}\right) \neq E V_{t}^{i}\left(h, \mathrm{e}^{*} ; \mathrm{c}^{j}\right) \\
& \sigma_{t}^{i *}(h, c)=0 \quad \text { otherwise }
\end{aligned}
$$

b. For the candidates: for all $j \in K$ and $h \in H_{t}$

$$
s_{t}^{j *}(h) \in \underset{c \in \mathbb{R}_{+}}{\arg \max _{t}} E W_{t}^{i}\left(h, e^{*} ; c\right) .
$$

Thus, $e^{*}$ is a growth equilibrium if it is a subgame perfect equilibrium to the finite horizon candidate/voter game with the additional stipulation that voters adopt dominant strategies at each stage of the game.

Let $\left\{h_{t}(k, T)\right\}_{t=1}^{T+1}$ be the optimal investment path for an individual with the median discount factor $\delta$, when the initial capital level is $k$ and there are $T+1$ periods, and let $\left\{g_{t}(k, T)\right\}_{t=0}^{T}$ be the corresponding consumption path. I. e.,

$$
g_{t}(k, T)=F\left(h_{t}(k, T)\right)-h_{t+1}(k, T) .
$$

Proposition 3, which is proven in the appendix, states that in a growth equilibrium, the consumption path is selected according to $g$.

PROPOSITION 3: For any $T \in N$, any growth equilibrium satisfies, for all $0 \leq t \leq T$ and $k \in \mathbb{R}_{+}$, 


$$
s_{t}^{1}(h, T)=s_{t}^{2}(h, T)=g_{0}\left(k^{t}(h), T-t\right)
$$

It follows that on the equilibrium path, consumption is given by $\left\{g_{t}(k, T)\right\}_{t}^{T}=0$.

Propositions 4 and 5, also proven in the appendix, state that as the time horizon goes to infinity, the growth equilibrium selects the optimal path for voter with the median discount factor, and such a path is an equilibrium for the infinitely repeated game.

PROPOSITION 4: $\left\{g_{t}(k, T)\right\}_{t=1}^{T}$ converges uniquely to the optimal path for the median voter in the infinite horizon model, $\left\{g_{t}(k)\right\}_{t=1}^{\infty}$.

PROPOSITION 5: Let $T=\infty$. Then, $(s, \sigma)$ is a growth equilibrium, where for all $t$ and $k, s_{t}^{1}(h)=s_{t}^{2}(h)=g_{0}\left(k^{t}(h)\right)$ and, for any $c=\left(c^{1}, c^{2}\right) \in \mathbb{R}_{+}^{2}$

$$
\sigma_{t}^{i}\left(h_{1} c\right)=\arg \max _{\delta \in k} E V_{t}^{i}\left(h, e, c^{\delta}\right) \text { if } E V_{t}^{i}\left(h, e, c^{1}\right) \neq E V_{t}^{i}\left(h, e, c^{2}\right) .
$$

\section{MULTI PERIOD COMMITMENT}

We now consider the case in which candidates can commit for some finite number $L$ of periods. To deal with this case, there are two problems we have to confront. The first involves what voters and candidates will conjecture will happen in the future, after the period to which they are commiting. The second is what policies to assume that candidates select for the $L$ periods of commitment in the absence of an equilibrium.

Regarding the first problem, in order to deal formally with finite length commitment one must specify expectations about what will happen after the period to which one can commit. The view we take here is that the problem at time $j L$ is identical to the problem at time 0 . The distribution of discount factors is the same at both points in time. Thus, it is reasonable to assume that the decision rule that is used at time $j L$ is the same for all $j$. Hence, we look for stationary policies, which are identical functions of the underlying preferences at each decision point.

Regarding the second problem, we already know from the results of section 3 that in the infinite horizon case, neoclassical optimal paths can be beaten by large 
majorities, and that there is no majority core among the set of feasible paths. Since these results only depended on perturbations of length 3, it is obvious that the same results will be true when candidates can commit for periods of length at least $L=3$. So what do we assume candidates do in the absence of a majority core?

In the absence of a majority core, one reasonable assumption is that candidates would choose a path that is as "safe" as possible. There are many ways of formulating such ideas in the social choice literature. The one we develop here is the idea of an $\alpha$ majority set - the set of policies that can be defeated by at most a majority of size $\alpha$, and the related idea of the minmax set - the set of policies that can be defeated by the smallest possible majority. For a justification of the minmax set as the outcome of models of two candidate competition, see Kramer [1977].

To develop these ideas, we first consider a simplified version of the problem, in which we ignore the continuation game, and consider only the $L$ period problem. For each $i \in N$, let $\underline{\delta}_{i}=\left(1, \delta_{i}, \delta_{i}^{2}, \ldots, \delta_{i}^{L-1}\right)$. Also, for any $c \in \mathcal{C}$, let $v(c)=\left(u\left(c_{0}\right), u\left(c_{2}\right), \ldots\right.$, $\left.u\left(c_{L-1}\right)\right)$. Then the $L$ period utility function of voter $i$ can be written in the form $V_{i}(\boldsymbol{c})=\underline{\delta}_{i} \cdot v(\boldsymbol{c})$, which is in the class of intermediate preferences (as defined by Grandmont [1978]).

Now for any $c^{*} \in \mathrm{C}$, let $Q=Q_{L}\left(c^{*}\right)=\left\{c \in \mathrm{C}_{:} c_{t}=c_{t}^{*}\right.$ for $\left.t \geq L\right\}$ be the set of feasible paths differing from $c^{*}$ on only the first $L$ periods. For any $c, c^{\prime} \in Q$ define $n\left(\boldsymbol{c}, \boldsymbol{c}^{\prime}\right)=\mid\left\{i \in N: V_{i}\left(\boldsymbol{c}^{\prime}\right)>V_{i}(\boldsymbol{c})\right\}$, to be the vote of $\boldsymbol{c}^{\prime}$ against $\boldsymbol{c}$, and $n(\boldsymbol{c})=\underset{\boldsymbol{c}^{\prime} \in Q}{\max }$ $n\left(\boldsymbol{c}, \boldsymbol{c}^{\prime}\right)$ to be the maximum vote in $Q$ against $\boldsymbol{c}$. Define $n^{*}=\min _{\boldsymbol{c} \in Q} n(\boldsymbol{c})$. Any $\boldsymbol{c} \in \stackrel{\boldsymbol{c}^{\prime}}{Q} \in \mathbf{Q}$ which $n(\boldsymbol{c})=n^{*}$ is called a minmax path. Given $1 / 2 \leq \alpha<1$, any $\boldsymbol{c} \in Q$ for which $n(\boldsymbol{c}) \leq \alpha n$ is called an $\boldsymbol{\alpha}$-majority path.

Using results of Kramer [1977], we can characterize any $\alpha$-majority path (and hence any minmax path) as a path $c \in Q$ which is optimal for an imaginary individual with discount vector $\boldsymbol{d}=\left(d_{0}, d_{1}, \ldots, d_{L-1}\right) \in \mathfrak{D}$, where $\mathfrak{D}=\operatorname{co}\left\{\underline{\boldsymbol{\delta}}_{i}: i \in N\right\}$. Further, if there are enough voters, $\boldsymbol{d}$ is an interior point of $\mathscr{D}$. Thus, we can write $\boldsymbol{d}=\sum_{i=1}^{n} \lambda_{i} \underline{\boldsymbol{\delta}}_{i}$, where $\lambda=\left(\lambda_{1}, \ldots, \lambda_{n}\right) \in \Delta^{n}$ is a weighting vector with $\lambda_{i}<1$ for all $i$.

LEMMA 1. Any interior point $\boldsymbol{d}$ of $\mathscr{D}$ exhibits increasing-marginal willingness to trade period $t-1$ consumption for period $t$ consumption. In other words, defining 
$\gamma_{t}=d_{t} / d_{t-1}$, it follows that $\gamma_{t}<\gamma_{s}$ for $t<s$

Thus, the general problem of finding an $\alpha$-majority path can be reformulated as that of finding an optimal path for an "imaginary" voter whose willingness to trade next period consumption for this period consumption is increasing over time. We therefore consider the problem of finding an optimum for such an imaginary voter when the voter can recommit every $L$ periods.

So let $\delta=\left(1, \delta_{1}, \delta_{2}, \ldots\right)$, be a discount vector where the discount structure may not satisfy the usual requirement that $\delta_{t}=\delta_{1}^{t}$. For $t \geq 1$, we define $\gamma_{t}=\delta_{t} / \delta_{t-1}$.

Let $h=\left(h_{1}, \ldots, h_{L}\right): \mathbb{R} \rightarrow \mathbb{R}^{L}$, represent the $L$ period policy function, where $h_{t}(k)$ represents the capital at the beginning of period $t$ if $k$ is the initial capital stock at time $t=0$. For notational convenience, we write $h_{0}(k)=k$. For any integer $j$, define $h_{j L+t}(k)=h_{t}\left(h_{L}^{j}(k)\right)$, and for any $h$, define

$$
v_{h}(k)=\sum_{t=0}^{\infty} \delta_{t+L} u\left(F\left(h_{t}(k)\right)-h_{t+1}(k)\right)
$$

Now, for any $h: \mathbb{R} \rightarrow \mathbb{R}^{L}, v: \mathbb{R} \rightarrow \mathbb{R}$, and $k \in \mathbb{R}$, define

$$
w(k ; h, v)=\sum_{t=0}^{L-1} \delta_{t} u\left(F\left(h_{t}(k)\right)-h_{t+1}(k)\right)+v\left(h_{L}(k)\right) .
$$

We want to find an $h$ such that for all $k$,

$$
h(k) \in \arg \max _{\hat{h}} w\left(k ; \hat{h}, v_{h}\right) .
$$

If there is a solution to problem (5.3), then for each initial capital $k_{0}=k$, in each period of commitment, the imaginary individual will choose to leave for the next commitment period the "correct" capital stock, $h_{L}(k)$. Thus, at this solution, the imaginary individual can be considered to be solving the $L$ period problem

subject to

$$
\max _{\left\{k_{t}\right\}} \sum_{t=0}^{L-1} \delta_{t} u\left(F\left(k_{t}\right)-k_{t+1}\right)=\max _{\left\{c_{t}\right\}} \sum_{t=0}^{L-1} \delta_{t} u\left(c_{t}\right)
$$

$$
k_{0} \text { given, } k_{L}=h_{L}\left(k_{0}\right) .
$$

Given the way we have formulated the problem, the individuals choosing at time $j L$ would use the vector $\delta$, and would make the conjecture that a similar vector would 
be used to make the decision at time $(j+1) L$, etc. In a stationary equilibrium, these conjectures would all be consistent and support beliefs that would make it optimal to leave the correct capital stock to the next commitment period.

If $h$ is a solution for (5.3), and $k$ is any initial capital stock, and write $k_{t}=h_{t}(k)$. We say that $\left\{k_{t}\right\}_{t=0}^{L}$ exhibits a political business cycle if $k_{0}=k_{L} \neq k_{t}$ for some $0<t<L$.

PROPOSITION 6: If $\gamma_{t} \neq \gamma_{s}$ for some $0<t, s<L$, then there is no solution to (5.3) that satisfies $k_{t}=k$ for all $t$. Any solution satisfying $k_{L}=k_{0}$, must yield a political business cycle.

It follows from Proposition 6 that at least in the limiting case, when steady state consumption has been reached, the minmax path exibits a political business cycle.

Note that while we have used the minmax set to motivate the above argument, the same argument would hold for any decision rule that selects an interior point of $\mathscr{D}$, (for example the mean of the individual discount vectors). We close with an example illustrating the solution to (5.3) for a special case.

EXAMPLE 2: In this example, we compute a solution to problem (5.1) - (5.3) for the case that $u(c)=\ln (c)$, and $F(k)=k^{\alpha}$, with $\alpha=.5$. We compute an example for 100 voters with discount factors uniformly distributed between .5 and 1.0. ${ }^{7}$ In this example, rather than computing the minmax vector, we have computed a solution for the average: $\lambda_{i}=1 / n$ for all $1 \leq i \leq n$.

To compute a solution, we choose a grid on $k$ (capital), and for any given $L$ proceed as follows:

1. Start with an initial guess $v(k)$ of $v_{h}(k)$ on the grid.

2. Compute $\widehat{h}(k) \in \arg \max _{\widehat{h}} w(k ; \widehat{h}, v)$ for each $k$ on the grid

3. Set $h(k)=\widehat{h}(k)$ on the grid.

${ }^{7}$ Experimental data on the distribution of individual discount factors can be found in Lazo [1992], who also give a review of other empirical and experimental work on this topic. For our purposes, the main finding is that there are significant differences in discount factors across individuals. 
4. Compute $\widehat{v}(k)=v_{h}(k)=\sum_{t=0}^{T} \delta_{t}+L^{u\left(F\left(h_{t}(k)\right)-h_{t+1}(k)\right)}$

5. If $|\widehat{v}-v|<\tau$ (in the $l_{1}$ norm) STOP.

6. Else, set $v(k)=\widehat{v}(k)$, and go to 2 .

We use as our grid $H=\{k=.002 \times j: j$ an integer with $0 \leq j \leq 200\}$. We set $T=150$, and $\tau=1.0 \times 10^{-10}$. In all the examples we have tried, we find the above program always converges (reaches STOP).

The solution to the above program, if it converges, yields (up to computer accuracy) a stationary optimal policy function, $h(k)=\left(h_{1}(k), \ldots, h_{L}(k)\right)$ defined on $H$. Given a stationary optimal policy function, we can generate a growth path from any initial capital stock, $k_{0}$ by using the definition of $h_{\ell}(k)$ for arbitrary $\ell=j L+t$ with $1 \leq t \leq L$ and $j \geq 0$. (We do a linear interpolation between $h_{t}\left(\left|h_{j L}(k)\right|\right.$ ) and $\left.h_{t}\left(\mid h_{j L}(k)\right\rfloor+1\right)$ to compute $h_{\ell}(k)$ for $\left.j>0\right)$.

Figure 1 illustrates optimal growth paths for the case when $L=3,6$, and 12 , respectively, and $k_{0}=.01$. In each figure the top line is output $\left(y_{t}=F\left(k_{t}\right)\right)$, the center line is consumption $\left(c_{t}=F\left(k_{t}\right)-k_{t+1}\right)$, and the bottom line is gross investment $\left(\iota_{t}=k_{t+1}-k_{t}\right)$. We note in the example that the political business cycles have the feature that output and consumption peak at the beginning and end of the electoral term, while investment peaks in the middle of the term. Also we note that the amplitude of the cyclical behavior increases as the length of the term increases.

\section{CONCLUSION}

The growth literature analyses optimal policies and competitive outcomes from the point of view of a representative consumer. In this paper, we investigate how the political process aggregates preferences of voters with different time preferences. What we find is that except for the case where the length of office is one period, the outcome of the political process will be different than the prediction given by the representative agent model. In particular, in the case of periodic elections, stationary minmax paths will behave like optimal business cycles. Unlike Nordhaus, the political business cycles are not caused by voter myopia, but by how the majortity relation aggregates preferences, and would be selected even at the beginning of the term of office. Our analysis also raises questions as to whether neoclassical optimal paths are socially 
desirable, since they can always be defeated by virtually unanımous majorities. In particular, cyclical paths are majority preferred to them and can only be defeated by smaller majorities. 


\section{APPENDIX A}

\section{PROOFS OF RESULTS IN SECTION 3}

Proof of Proposition 1: Since the game (3.1) is zero sum and symmetric, if there is any Nash equilibrium, there is a symmetric equilibrium, of the form $(\boldsymbol{c}, \boldsymbol{c})$.

We first note that $(\boldsymbol{c}, \boldsymbol{c})$ is a Nash equilibrium of the game (3.1) if and only $\boldsymbol{c}$ is a majority rule core. Clearly if $(\boldsymbol{c}, \boldsymbol{c})$ is a Nash equilibrium of the game then $\boldsymbol{c}$ is a majority rule core. To prove the converse, first note that from the assumptions on $u$, it follows that for all $i, U_{i}$ is strictly quasi concave over $\mathrm{e}: U_{i}\left(\boldsymbol{c}^{\prime}\right) \geq U_{i}(\boldsymbol{c}) \Rightarrow$ $U_{i}\left(\lambda c+(1-\lambda) c^{\prime}\right)>U_{i}(\boldsymbol{c})$ for all $0<\lambda<1$. Assume that $\boldsymbol{c}$ is a majority rule core, but $(\boldsymbol{c}, \boldsymbol{c})$ is not a Nash equilibrium. Then there is a $\boldsymbol{c}^{\prime}$ with $n\left(\boldsymbol{c}, \boldsymbol{c}^{\prime}\right)>n\left(\boldsymbol{c}^{\prime}, \boldsymbol{c}\right)$. Taking $\boldsymbol{c}^{\prime \prime}=\left(\boldsymbol{c}+\boldsymbol{c}^{\prime}\right) / 2$, it follows that $n\left(\boldsymbol{c}, \boldsymbol{c}^{\prime \prime}\right)>n / 2$. This contradicts the assumption that $c$ is a majority rule core.

Thus, we need only show that there is no majority core. Proceed by contradiction and assume that $c^{*} \in \mathfrak{e}$, is a majority core. By the assumption that all voters have $u^{\prime}(0)=\infty$, it follows that any path for which $c_{t}=0$ for some $t$ is Pareto dominated. Also, since $c_{t}=F\left(k_{t}\right) \Rightarrow k_{t+1}=0 \Rightarrow c_{s}=0$ for all $s>t$, any path with $c_{t}=F\left(k_{t}\right)$ is Pareto dominated. Thus, we can assume without any loss of generality that $0<c_{t}<F\left(k_{t}\right)$ for all $t$. We now pick $\tau \geq 0$, and $m>1$, and define

$Q=\left\{c \in \mathrm{C}: 0<c_{t}<F\left(k_{t}\right)\right.$ for all $t$, and $\mathrm{c}_{t}=\mathrm{c}_{t}^{*}$ for $t<\tau$, and $\left.t \geq \tau+m\right\}$,

and

$Q^{*}=\left\{\left(\mathrm{c}_{0}, \ldots, c_{m-1}\right):\right.$ for some $\mathrm{c}^{\prime} \in Q, c_{\tau+t}^{\prime}=c_{t}$ for $\left.0 \leq t \leq m-1\right\}$.

Note $Q$ and $Q^{*}$ are non-empty since $c^{*} \in Q$. Clearly $Q \subseteq \mathcal{e}$, so if we can find $c \in Q$ which majority defeats $c^{*}$, then we are done. Also, for any $c \in Q, U_{i}(c)-U_{i}\left(c^{*}\right)=$ $\delta_{i}^{\tau}\left\{\sum_{t=0}^{m-1} \delta_{i}^{t}\left[u\left(c_{\tau+t}\right)-u\left(c_{\tau+t}^{*}\right)\right]\right\}$. So

$$
U_{i}(c)>U_{i}\left(c^{*}\right) \Leftrightarrow \sum_{t=0}^{m-1} \delta_{i}^{t}\left[u\left(c_{\tau+t}\right)-u\left(c_{\tau+t}^{*}\right)\right]>0
$$

Thus, for $c^{*} \in Q$, to determine if $U_{i}(c)>U_{i}\left(c^{*}\right)$, it is sufficient to define $m$ period utility functions $V_{*}: \mathbb{R}_{+}^{m} \rightarrow \mathbb{R}$ by $V_{i}^{(}\left(x_{0}, \ldots, x_{m-1}\right)=\sum_{t}^{m-1} \delta_{i}^{t} u\left(x_{*}\right)$, define $x^{*}=\left(x_{0}^{*}, \ldots, x_{m-1}^{*}\right)=\left(c_{\tau}^{*}, \ldots, c_{\tau+m-1}^{*}\right.$, and then check if $V_{i}(\overline{\bar{x})})^{\prime} V_{i}\left(x^{*}\right)$ for any
$x \in Q^{*}$. Thus, the problem reduces to showing that $x^{*}$ is not a majority core in $Q^{*}$ under the preferences $\left\{V_{i}\right\}_{i \in N}$ for some $\tau \geq 0$ and $m>1$.

Now $Q$, and hence $Q^{*}$, is a $(m-1)$-dimensional differentiable manifold in which contains $c^{*}$ as a relative interior point. To see this, we can write

$$
\begin{aligned}
Q^{*}= & \left\{\left(c_{0}, \ldots, c_{m-1}\right): 0<c_{0}<k_{\tau}^{*}, 0<c_{1}<F\left(k_{\tau}^{*}-c_{0}\right),\right. \\
& 0<c_{2}<F\left(F\left(k_{\tau}^{*}-c_{0}\right)-c_{1}\right), \ldots, \\
& 0<c_{m-2}<F\left(\ldots\left(F\left(k_{\tau}^{*}-c_{0}\right)-c_{1}\right) \ldots-c_{m-3}\right), \\
& \left.F\left(\ldots\left(F\left(k_{\tau}^{*}-c_{0}\right)-c_{1}\right) \ldots-c_{m-1}\right)=k_{\tau+m-1}^{*}\right\} .
\end{aligned}
$$

Since $F$ is invertible and $F(0)=0, Q^{*}$ can be rewritten as $Q^{*}=\left\{\left(c_{0}, \ldots, c_{m-1}\right)\right.$ : $0<g_{j}(c)<k_{\tau}^{*} \quad$ for $\left.\quad 0 \leq j \leq m-2, \quad g_{m-1}(c)=0\right\}$, where $g_{0}(c)=c_{0}$, $g_{1}(c) \stackrel{J^{\prime}=F^{-1}}{=}\left(c_{1}\right)+c_{2}, \quad g_{2}(c)=F^{-1}\left(F^{-1}\left(c_{2}\right)+c_{1}\right)+c_{0}, \quad \ldots, \quad g_{m-2}(c)=F^{-1}(\quad \ldots$ $\left(F^{-1}\left(F^{-1}\left(c_{m-2}\right)+c_{m-3}\right)+\ldots+c_{1}\right)+c_{0}$, and $g_{m-1}(c)=F\left(\ldots\left(F\left(k_{\tau}^{*}-c_{0}\right)-c_{1}\right)\right.$

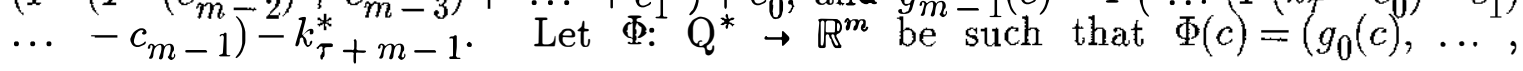


$\left.g_{m-1}(c)\right)$. Since $F^{-1}$ is $C^{1}, \Phi$ is $C^{1}$, and since $F^{-1}$ is $1-1, \Phi$ is $1-1$. Further one can check that $d \Phi / d c$ is non singular. Also $Q^{*}=\Phi^{-1}\left[\left(0, k_{\tau}^{*}\right)^{m^{-1}} \times\{0\}\right]$. So $\Phi$ is a $C^{1}$ diffeomorphism of $\mathrm{Q}^{*}$ onto $\left(0, k_{\tau}^{*}\right)^{m^{-1}} \times\{0\}$, and $\left(0, k_{\tau}^{*}\right)^{m^{-1}} \subseteq \mathbb{R}^{m-1}$ is clearly open. Thus, $\mathrm{Q}^{*}$ is a $C^{1}$ manifold.

The intuition is that we can make small independent perturbations of $c_{\tau}^{*}$ through $c_{\tau+m-2}^{*}$, and then get back on the original path $c^{*}$ in period $\tau+m$ by selecting $c_{\tau+m_{*}-1}$ to generate the same capital stock, $k_{\tau+m_{*}^{*}}^{*}$ as that associated with the path $c^{*}$ at period $\tau+m$. Thus, in a neighborhood of $x^{*}$, we can write

$$
Q^{*}=\left\{x \in \mathbb{R}_{+}^{m}: q(x)=0\right\}
$$

where $q: \mathbb{R}_{+}^{m} \rightarrow \mathbb{R}$ is a differentiable function, invertible at $x^{*}$. (In fact $q=g_{m}$ in the above construction). Write $q^{*}=\left(q_{0}^{*}, \ldots q_{m}^{*} 1\right)=\nabla q\left(x^{*}\right) \in \mathbb{R}^{m}$, and $v_{i}^{*}=\left(v_{i 0}^{*}, \ldots\right.$ ,$\left.v_{i, m-1}^{*}\right)=\nabla V_{i}\left(x^{*}\right)=\left(u^{\prime}\left(x_{0}^{*}\right), \ldots, \delta_{i}^{m-1} u^{\prime}\left(x_{m-1}^{*}\right)\right)$.

Now it follows from results of Plott [1967], generalized by McKelvey and Schofield [1987], that for $x^{*}$ to be a majority core in $Q^{*}$, with the preferences $\left\{V_{i}\right\}_{i \in N}$, there must be one voter $j \in N$, with a utility gradient $v_{j}^{*}$ in the space spanned by $q^{*}$, and for any other voter, $k \in N-\{j\}$, there is a voter $\imath(k) \in N-\{j, k\}$ such that $v_{k}^{*}$ is in the space spanned by $v_{i(k)}^{*}$ and $q^{*}$.

It is sufficient to let $m=3$. Then $v_{i}^{*}=\left(u^{\prime}\left(x_{0}^{*}\right), \delta_{i} u^{\prime}\left(x_{1}^{*}\right), \delta_{i}^{2} u^{\prime}\left(x_{2}^{*}\right)\right)=\left(w_{0}, \delta_{i} w_{1}\right.$, $\left.\delta_{i}^{2} w_{2}\right)$, where $w_{j}=u^{\prime}\left(x_{j}^{*}\right)$ for $j=0,1,2$. Now consider any three voters, $i$, $j$, and $k$, with $\delta_{i}<\delta_{j}<\delta_{k}$, and let $A=\left[v_{\ell}^{*}\right]$ be the $3 \times 3$ matrix whose rows are the gradient vectors $v_{i}^{*}, v_{j}^{*}$, and $v_{k}^{*}$, respectively. Then $\operatorname{det} A=w_{0} w_{1} w_{2}\left(\delta_{j}-\delta_{j}\right)\left(\delta_{k}-\delta_{j}\right)\left(\delta_{i}-\delta_{k}\right)$ $\neq 0$. It follows that $v_{i}^{*}, v_{j}^{*}$, and $v_{k}^{*}$ are linearly independent. Since any three voters have utility gradients that are linearly independent, it follows that the symmetry conditions for a core point are not met at $x^{*}$. Hence $x^{*}$ is not a majority core.

The above proof can also be extended to the case in which all voters have different one-stage utility functions as well as different discount factors: The symmetry conditions for a constrained core point tell us that the consumption path must be a constrained optimum for at least one voter. But by the results of section 2 , it follows that the consumption path must be a sequence that converges monotonically to a point $c^{*}$. Thus, $\lim _{t \rightarrow \infty} c_{t}^{*}=c^{*}$. For any $\tau \geq 0, m=3$, and $i \in N$, define $v_{i_{*}}^{*}=\left(u_{i}^{\prime}\left(c_{\tau}^{*}\right), \delta_{i} u_{i}^{\prime}\left(c_{\tau+1}^{*}\right), \delta_{i}^{2} u_{i}^{\prime}\left(c_{\tau+2}^{*}\right)\right)$. Also, define $v_{i}^{*}=w_{i}\left(1, \delta_{i}, \delta_{i}^{Q}\right)$, where $w_{i}=u_{i}^{\prime}\left(c^{*}\right)$. Select any three voters, $i, j$, and $k$, and define $A_{\tau}=\left[v_{\ell_{T}}^{*}\right]$ to be the $3 \times 3$ matrix with rows $v_{j \tau}^{*}, v_{j \tau}^{*}$, and $v_{k \tau}^{*}$, respectively, and $A=\left[v_{\ell}^{*}\right]_{*}$ to be the matrix with rows $v_{i}^{*}, v_{j}^{*}$, and $v_{k}^{*}$, respectively. It follows that as $\tau \rightarrow \infty, v_{\ell \tau}^{*} \rightarrow v_{\ell}^{*}$ for $\ell \in\{i, j, k\}$. So $A_{\tau} \rightarrow A$. Since the determinant is a continuous function of $A$, it follows that $\operatorname{det} A_{\tau} \rightarrow \operatorname{det} A=w_{1} w_{2} w_{g}\left(\delta_{i}-\delta_{j}\right)\left(\delta_{k}-\delta_{j}\right)\left(\delta_{i}-\delta_{k}\right) \neq 0$. Hence, for large enough $\tau, \operatorname{det} A_{\tau} \neq 0$. If we pick $\tau$ large enough so that $\operatorname{det} A_{\tau} \neq 0$ for all triples of voters, then the symmetry conditions for a constrained majority core are not met for the $Q^{*}$ defined by this $\tau$. Thus, there is no majority core. ${ }^{8}$

Proof of Proposition 2: Let $c^{*} \in \mathcal{C}$ be a neoclassical optimal path. Thus, there is a $\delta$ such that $c^{*}$ is optimal for the objective function $!_{t=0}^{\infty} \delta^{t} u\left(c_{t}\right)$. Let $N_{\delta}=\{j \in N$ :

\footnotetext{
${ }^{8}$ It is an open question whether we can find a path that majority defeats $c^{*}$ with $\tau$ near 0 .
} 
$\left.\delta_{j} \neq \delta\right\}$. By assumption, $\left|N_{\delta}\right| \geq n-1$. Define $Q, Q^{*}$ and $V_{j}$ as in the previous proof, where $\tau=-1$, and $m=\overline{3}$. Write $\underline{\boldsymbol{c}}_{2}^{*}=\left(c_{0}^{*}, c_{1}^{*}, c_{2}^{*}\right)$. For each voter $j \in N$, write $v_{j}=\nabla V V_{j}\left(\underline{c}^{*}\right)=\left(w_{0}, \quad \delta_{j} w_{1}, \delta_{j}^{2} w_{2}\right)$, where $w_{i}=u^{\prime}\left(c_{i}^{*}\right)$, and $v=\left(w_{0}, \delta w_{1}, \delta^{2} w_{2}\right)$. Now for any scalar $a>0$, define

$$
z=\boldsymbol{a}\left(\delta^{2}\left[\frac{w_{2}}{w_{0}}\right],-2 \delta\left[\frac{w_{2}}{w_{1}}\right], 1\right) .
$$

Then for any $j \in N$ we have

$$
z \cdot v_{j}=a w_{2}\left[\delta^{2}-2 \delta \delta_{j}+\delta_{j}^{2}\right]=a w_{2}\left(\delta-\delta_{j}\right)^{2} .
$$

It follows that $z \cdot v=0$, and $z \cdot v_{j}>0$ for all $j \in N_{\delta}$. Let $x=\underline{c}^{*}+z$. Since all $V_{j}$ are differentiable, it is clear that for choice of $a$ small enough $V_{j}(x)>V_{j}\left(\underline{c}^{*}\right)$ for all $j \in N_{\delta}$. We henceforth assume that $a$ is chosen so that this is satisfied.

The consumption path generated by $x$ need not be feasible. To construct a feasible path, we need to perturb $x$ to get it to satisfy the constraint while maintaining the strict preferences of all voters in $N_{\delta}$ : As in the previous proposition, since $\boldsymbol{c}^{*}$ is neoclassical optimal, $\underline{c}^{*}$ is relative interior to $Q^{*}$. So in a neighborhood of $\underline{c}^{*}$ we can write $\mathrm{Q}^{*}=\left\{x \in \mathbb{R}_{+}^{3}: q(x)=0\right\}$ where $q(x)=x_{2}+k_{3}-F\left(F\left(\bar{F}\left(k_{0}\right)-x_{0}\right)-x_{1}\right)$ is differentiable. Also, since $c^{*}$ is optimal, we know that there is a scalar $b$ such that $\boldsymbol{v}=b q^{*}$, where $\boldsymbol{q}^{*}=\left(1,1 / F^{\prime}\left(k_{1}^{*}\right)\right.$, $\left.1 / F^{\prime}\left(k_{1}^{*}\right) F^{\prime}\left(k_{2}^{*}\right)\right)=\nabla q\left(\underline{c}^{*}\right)$ is the vector normal to the constraint, $Q^{*}$, at $\underline{c}^{*}$. Pick $\epsilon>0$ so that $V_{j}\left(x-\epsilon \boldsymbol{q}^{*}\right)>V_{j}\left(\underline{c}^{*}\right)$ and $V_{j}\left(x+\epsilon \boldsymbol{q}^{*}\right)>V_{j}\left(\underline{c}^{*}\right)$ for all $j \in \bar{N}_{\delta^{*}}$. Set $\boldsymbol{y}_{1}=z-\epsilon \boldsymbol{q}^{*}$, and $\boldsymbol{y}_{2}=\boldsymbol{z}+\epsilon \boldsymbol{q}^{*}$. Then $\boldsymbol{y}_{1} \cdot \boldsymbol{q}^{*}=-\epsilon \boldsymbol{q}^{*} \cdot \boldsymbol{q}^{*}<0$, and $\boldsymbol{y}_{2} \cdot \boldsymbol{q}^{*}=\epsilon \boldsymbol{q}^{*} \cdot \boldsymbol{q}^{*}>0$. It follows that we can find $\eta_{0}>0$ such that $q\left(\underline{c}^{*}+\eta \boldsymbol{y}_{1}\right)<q\left(\underline{\boldsymbol{c}}^{*}\right)$ and $q\left(\underline{\boldsymbol{c}}^{*}+\eta \boldsymbol{y}_{2}\right)>q\left(\underline{\boldsymbol{c}}^{*}\right)$ for all $0<\eta<\eta_{0}$. Let $\eta^{*}$ be the minimum of $\eta_{0}$ and 1 . But then, setting $z_{1}=\underline{c}^{*}+\eta^{*} \boldsymbol{y}_{1}$ and $z_{2}=\underline{c}^{*}+\eta^{*} \boldsymbol{y}_{2}$, it follows that $q\left(z_{1}\right)<q\left(\underline{c}^{*}\right)$, $q\left(z_{2}\right)>q\left(\underline{c}^{*}\right)$, and $\overline{V_{j}}\left(z_{\ell}\right)>V_{j}\left(\underline{\boldsymbol{c}}^{*}\right)$ for $\ell \in\{1,2\}$, and $j \in N_{\delta}$. By continuity of $q$,

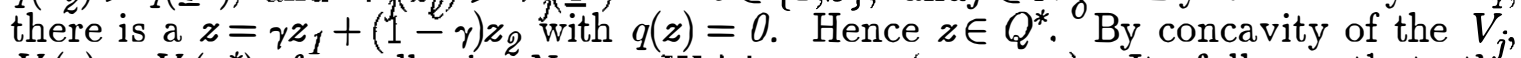
$V_{j}(z)>V_{j}\left(\underline{c}^{*}\right)$ for all $j \in N_{\delta}$. Writing $z=\left(z_{0}, z_{1}, z_{2}\right)$, It follows that the consumption path $\boldsymbol{c}^{\prime}=\left(z_{0}, z_{1}, z_{2}, c^{*}, c^{*}, \ldots, \mathrm{c}^{*}, \ldots\right)$, is a feasible consumption path such that $U_{j}\left(\boldsymbol{c}^{\prime}\right)>U_{j}\left(c^{*}\right)$ for all $j \in N_{\delta^{\prime}}$. Since $\left|N_{\delta}\right| \geq n-1$, this proves the first assertion. If there is no voter with $\delta_{j}=\delta$, then $\left|N_{\delta}\right|=n$, proving the second assertion. The last assertion in the proposition follows since our construction only required three consecutive periods of perturbation.

\section{B. PROOFS OF RESULTS IN SECTION 4}

First we need to introduce some additional notation and prove a preliminary lemma. Define $\left\{h_{f, k}(k, T)\right\}_{t=1}^{T+1}$ to be a solution to the following problem:

such that

$$
\max _{\left\{k_{t}\right\}_{t=0}^{T}}\left\{\sum_{t=0}^{T_{t}} \delta^{t} u\left[F\left(k_{t}\right)-k_{t+1}\right]\right\}
$$

$$
0 \leq k_{t+1} \leq F\left(k_{t}\right), t=0,1, \ldots, T
$$

and

$$
k_{0}=k>0 \text {. }
$$

Since $u^{\prime}(0)=\infty$ the inequalities do not bind except for $k_{T+1}$. Furthermore the objective function is strictly concave and thus there is exactly one solution to 
the problem which is given by the following conditions:

$$
\begin{aligned}
& \delta F^{\prime}\left(k_{t}\right) u^{\prime}\left[F\left(k_{t}\right)-k_{t+1}\right]=u^{\prime}\left[F\left(k_{t-1}\right)-k_{t}\right] \text { for } t=1,2, \ldots, T, \\
& k_{T+1}=0, k_{0}=k .
\end{aligned}
$$

Let $v^{t}(k)$ be the value function for the median discount factor when the investment path voter $\left\{k_{t}\right\}=\left\{k_{t}(k, T-t)\right\}_{t=0}^{t=t+1}$ is selected. I. e.,

$$
v^{t}(k)=\sum_{t=0}^{T} \delta^{t} u\left[F\left(k_{t}\right)-k_{t+2}\right]
$$

By standard arguments, $v^{t}(k)$ is strictly concave.

The following lemma gives a monotonicity property of optimal paths in the finite horizon setting:

LEMMA: Let $\left\{k_{t}\right\}_{t=1}^{T}$ and $\left\{\tilde{k}_{t}\right\}_{t=1}^{T}$ be two optimal growth paths for a voter with discount factor $\delta$, where $k_{0}>k_{0}$. Then,

$$
F\left(k_{t}\right)-k_{t+1}>F\left(\widetilde{k}_{t}\right)-\widetilde{k}_{t+1}, \text { for } t=1, \ldots, T \text {. }
$$

Proof: Suppose the lemma does not hold. Let $T$ be the smallest positive integer for which the inequality does not hold and let $\left\{k_{t}\right\}_{t=1}^{T},\left\{\hat{k}_{t}\right\}_{t \sim 1}^{T}$ be two optimal growth sequences for which the lemma does not hold. Suppose $\bar{k}_{1} \geq k_{1}$. Then

$$
\begin{aligned}
& -k_{1} \geq-\widetilde{k}_{1} \Rightarrow F\left(k_{0}\right)-k_{1}>F\left(\widetilde{k}_{0}\right)-\widetilde{k}_{1} \\
& \Rightarrow u^{\prime}\left[\delta\left(k_{0}\right)-k_{1}\right]<u^{\prime}\left[\delta\left(\widetilde{k}_{0}\right)-\widetilde{k}_{1}\right] .
\end{aligned}
$$

The first order conditions then give

$$
\delta F^{\prime}\left(k_{1}\right) u^{\prime}\left[F\left(k_{1}\right)-k_{2}\right]<\delta F^{\prime}\left(\widetilde{k}_{1}\right) u^{\prime}\left[F\left(\widetilde{k}_{1}\right)-\widetilde{k}_{2}\right]
$$

Thus

and

$$
u^{\prime}\left[F\left(k_{1}\right)-k_{2}\right]<u^{\prime}\left[F\left(\widetilde{k}_{1}\right)-\widetilde{k}_{2}\right]
$$

$$
\widetilde{k}_{2}>k_{2}
$$

By repeatedly using the first order conditions we get that $\widetilde{k}_{t}>k_{t}$ for $t \equiv 2, \ldots T+1$. But this is not possible since $\widetilde{k}_{T+1}=k_{T+1}=0$. Therefore, $k_{1}>\widetilde{k}_{1}$ and $T>1$. Furthermore let

$$
\begin{aligned}
l_{t} & =k_{t+1} \\
\widetilde{l}_{t} & =\widetilde{k}_{t+1}, \text { for } t=1, \ldots, T-1 .
\end{aligned}
$$

Then $\left\{l_{t}\right\}_{t=1}^{T-1},\left\{\tilde{l}_{t}\right\}_{t=1}^{T-1}$ are two optimal growth sequences for which the lemma does not hold, contra $\overline{\bar{d}}$ icting the minimality of $T$.

Proof of Proposition 3: The proof is by induction on the time horizon, $T$. If $T=0$, then $s_{0}^{2}(h, T)=F\left(h_{0}(k, T)\right)=F(k)=g_{0}(k, 0)$ is clearly the only Nash equilibrium for the candidates, since all voters' one period utility functions are monotonic in consumption. Further, any undominated strategy for a voter must have the property that the voter always votes for the candidate offering the highest level of consumption, abstaining only if there is a tie.

Now we assume the result is true for $T-1$, and show it is true for $T$. Thus, 
suppose that for all $t>0$, and all $k, s_{t}^{i}(h, T)=g_{0}\left(k^{t}(h), T-t\right)$ are subgame perfect responses. Suppose that $s_{0}^{i}(k, T) \neq g_{0}(k, T)$. If $s_{0}^{i}(k, T)>g_{0}(k, T)$, then $F(k)-s_{0}^{i}(h, T)<F(k)-g_{0}(k, T)$. By the monotonicity of $g_{t}$, proved in the above Lemma, and the monotonicity of $u$,

$$
u\left(g_{t}\left(F(k)-g_{0}(k, T), T-1\right)\right)-u\left(g_{t}\left(F(k)-s_{0}^{i}(k, T), T-1\right)\right)>0 .
$$

Note that $E V_{1}^{m}\left(h, e^{*}, c\right)$ is strictly concave in $c$ (see Harris [1987]) Let $c^{*}=g(k)$ be the (unique) maximum of $E V_{1}^{m}$ in $\left[0, F\left(k^{1}(h)\right)\right]$. Now pick $j \in K$, and pick $c^{j} \in\left[0, F\left(k^{1}(h)\right)\right]$ with $c^{j} \neq c^{*}$. There are two cases.

If $c^{j}>c^{*}$, then, using the monotonicity of $g_{t}(k, T-1)$ in $k$ for all $t \geq 1$, and the monotonicity of $u(c)$ in $c$, we get $c^{j}>c^{*} \Rightarrow F(k)-c^{j}<F(k)-c^{*} \Rightarrow$ $g_{t}\left(F(k)-c^{j}, T-1\right) \quad<g_{t}\left(F(k)-c^{*}, T-1\right) \quad$ for $\quad$ all $t \geq 1 \Rightarrow$ $u\left(g_{t}\left(F(k)-c^{*}, T-1\right)\right)-u\left(g_{t}\left(F(k)-c^{j}, T-1\right)\right)>0$ for all $t \geq 1$. But then, if $\delta_{i} \geq \delta_{m}$, we have

$$
\begin{aligned}
& E V_{0}^{i}\left(h, e^{*} ; c^{*}\right)-E V_{0}^{i}\left(h, e^{*} ; c^{j}\right) \\
& =u\left(c^{*}\right)-u(c)+\delta_{i} \sum_{t} \delta_{i}^{t}\left[u\left(g_{t}\left(F(k)-c^{*}, T-1\right)\right)-u\left(g_{t}\left(F(k)-c^{j}, T-1\right)\right)\right] \\
& \geq u\left(c^{*}\right)-u(c)+\delta_{m} \sum_{t} \delta_{m}^{t}\left[u\left(g_{t}\left(F(k)-c^{*}, T-1\right)\right)-u\left(g_{t}\left(F(k)-c^{j}, T-1\right)\right)\right] \\
& =E V_{0}^{m 2}\left(h, e^{*} ; c^{*}\right)-E V_{0}^{m}\left(h, e^{*} ; c^{j}\right)>0 .
\end{aligned}
$$

Hence, $E V_{0}^{i}\left(h, e^{*} ; c^{*}\right)>E V_{0}^{i}\left(h, e^{*} ; c^{j}\right)$ for all i with $\delta_{i} \geq \delta_{m}$. If $c^{j}<c^{*}$, a similar argument establishes that $E V_{0}^{i}\left(h, e^{*} ; c^{*}\right)>E V_{0}^{i}\left(h, e^{*} ; c^{3}\right)$ for all $i$ with $\delta_{i} \leq \delta_{m}$. It follows that in both cases, we have

$$
\begin{aligned}
& \Phi_{0}^{j}\left(h,\left(c^{*}, s^{-j *}(h)\right), \sigma^{*}\right)=\Phi_{0}^{j}\left(h,\left(c^{*}, c^{*}\right), \sigma^{*}\right)=0 \\
& \quad>\left|\left\{i \in N: E V_{0}^{i}\left(h, e^{*} ; c^{j}\right)>E V_{0}^{i}\left(h, e^{*} ; c^{*}\right)\right\}\right| \\
& \quad-\left|\left\{i \in N: E V_{0}^{i}\left(h, e^{*} ; c^{*}\right)>E V_{0}^{i}\left(h, e^{*} ; c^{j}\right)\right\}\right| \\
& =\left|\left\{i \in N: \sigma_{0}^{i}\left(h,\left(c^{j}, c^{*}\right)\right)=j\right\}\right|-\left|\left\{i \in N: \sigma_{0}^{i}\left(h,\left(c^{j}, c^{*}\right)\right) \in k-\{j\}\right\}\right| \\
& =\Phi_{0}^{j}\left(h,\left(c^{j}, c^{*}\right), \sigma^{*}\right)=\Phi_{0}^{j}\left(h,\left(c^{j}, s^{-j *}(h)\right), \sigma^{*}\right) .
\end{aligned}
$$

Hence $\left.\Phi_{j}\left(h,\left(c^{j}, s^{-j *}(h)\right)\right), \sigma^{*}\right)$ is maximized at $c^{j}=c^{*}$. This proves the result.

Proof of Proposition 4: Fix $k$, and let $\delta$ be the discount factor of the median voter. For $T \in \mathbb{Z} \cup\{\infty\}$, let $F^{T} \subseteq[0, \bar{c}]^{T}$ be the set of feasible consumption paths for the $T$ period model, when the initial capital stock is $k$. For $c \in F^{T}$, write $V^{T}(c)$ $=\sum_{t=1}^{T} \delta^{t} u\left(c_{t}\right)$. For $T \in \mathbb{Z}$, define $c_{t}^{T}=g_{t}(k, T)$ and $c_{t}^{*}=g_{t}(k)$. So

and

$$
c^{T}=\underset{c \in F^{T}}{\arg \max } V^{T}(c)
$$

$$
c^{*}=\underset{c \in F^{\infty}}{\arg \max } V^{\infty}(c) \text {. }
$$

By the assumptions on $u$, and $\delta$, it follows that for all $T \in \mathbb{Z} \cup\{\infty\}, V^{T}\left(c^{T}\right)<\infty$. Define $\widetilde{c}^{T} \in F^{\infty}$ by

$$
\tilde{c}_{t}^{T}= \begin{cases}c^{T} & \text { if } t \leq T \\ 0 & \text { if } t>T .\end{cases}
$$


Note that $F^{\infty}$ is compact with the product topology. Thus there exists a sequence $\left\{T_{i}\right\}_{i}$, and a $\widetilde{c} \in F^{\infty}$ such that $\widetilde{c}^{T_{i}} \rightarrow \widetilde{c}$. Let $\epsilon>0$. Choose $\bar{T}$ such that

$$
\sum_{t=\bar{T}}^{\infty} \delta^{t} u(\bar{c})<\frac{\epsilon}{2}
$$

Choose $I$ such that $i>I$ implies

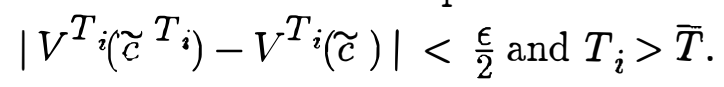

Then

$$
\begin{aligned}
& V^{\infty}(\widetilde{c}) \leq V^{\infty}\left(c^{*}\right) \leq V^{T_{i}}\left(\widetilde{c}^{T_{i}}\right)+\frac{\epsilon}{2} \leq V^{T_{i}}(\widetilde{c})+\epsilon \leq V^{\infty}(\widetilde{c})+\epsilon \\
& \Rightarrow V^{\infty}(\widetilde{c})=V^{\infty}\left(c^{*}\right) \Rightarrow \widetilde{c} \in \arg \max V^{\infty}(c) .
\end{aligned}
$$

Finally, uniqueness follows because the $\mathrm{e}^{c \epsilon F^{\infty}}$ set of optimal paths for the infinite horizon model is convex, and any strict convex combination is strictly better.

Proof of Proposition 5: Suppose $(s, \sigma)$ is not a growth equilibrium. There are two possible cases:

(i) Suppose there exists $s^{j \prime}$ and $h \in H^{t}$ such that

$$
E W_{j}\left(h, e^{-j}, s^{j \prime}\right)>E W_{j}\left(h, e^{-j}, s^{j}\right) .
$$

Then there exists $T>0$ such that

$$
E\left[\sum_{t=1}^{T} \delta_{j}^{t} \rho_{j}^{t}\left(h_{t}^{t}\left(h, e^{\prime}\right), e^{\prime}\right)\right]>E\left[\sum_{t=1}^{T} \delta_{j}^{t} \rho_{j}^{t}\left(h_{t}^{t}(h, e), e\right)\right]
$$

where $e^{\prime}=\left(\bar{e}^{\prime}, s^{j \prime}\right)$. We know that ${ }^{t}=1$ is an equilibrium to the game with horizon $t+T$.

Thus a contradiction.

$$
E\left[\sum_{t=1}^{T} \delta_{j}^{t} \rho_{j}^{t}\left(h_{t}^{t}\left(h, e^{\prime}\right), e^{\prime}\right)\right] \leq E\left[\sum_{t=1}^{T} \delta_{j}^{t} \rho_{j}^{t}\left(h_{t}^{t}(h, e), e\right)\right]
$$

(ii) Suppose that there is a $\sigma^{i \prime}$ and $h \in H^{t}$ such that

$$
E V_{i}\left(h, e^{-i}, \sigma^{i \prime}\right)>E V_{i}(h, e)
$$

The same type of argument yields a contradiction.

\section{PROOFS OF RESULTS IN SECTION 5}

Proof of Lemma 1: Use the fact that $x^{-1}$ is a strictly convex function of $x$. Then using Jensen's inequality,

$$
\frac{1}{\gamma_{t}}=\sum_{i}\left[\frac{\lambda_{i} \delta_{i}^{t}}{\sum_{j}, \lambda_{j} \delta_{j}^{t}}\right]\left(\delta_{i}\right)^{-1}>\left(\sum_{i}\left[\frac{\lambda_{i} \delta_{i}^{t}}{\sum_{j} \lambda_{j} \delta_{j}^{t}}\right] \cdot \delta_{i}\right)^{-1}=\frac{1}{\gamma_{t+1}}
$$

Proof of Proposition 6: Assume that $h$ is a solution for (5.3). Let $k \in \mathbb{R}$ be any initial capital stock, and write $k_{t}=h_{t}(k)$. Then the $k_{t}$ 's will satisfy the first order conditions:

$$
\begin{aligned}
& u^{\prime}\left(F\left(k_{t-1}\right)-k_{t}\right)=\gamma_{t} F^{\prime}\left(k_{t}\right) u^{\prime}\left(F\left(k_{t}\right)-k_{t+1}\right), \text { for } 0<t<L \\
& \delta_{L-1} u^{\prime}\left(F\left(k_{L-1}\right)-k_{L}\right)=v_{h}^{\prime}\left(k_{L}\right)
\end{aligned}
$$


where $\gamma_{t}=\delta_{t} / \delta_{t-1}$. It follows immediately that there is a solution for the first $L$ equations that satisfies $k_{t}=k$ for all $t$ only if $1=\gamma_{t} F^{\prime}(k)$ for all $0<t<L$ which occurs only if all the $\gamma_{t}$ 's are equal. Therefore, if $\gamma_{t} \neq \gamma_{s}$ for some $t, s$, then for any $k$ satisfying $k_{0}=k_{L}=k$, there must be a $j$ for which $k_{j} \neq k$. But this is a political business cycle.

Computations for Example 2. The problem to be solved is:

such that

$$
\max _{\left\{k_{t}\right\}} \sum_{t=1}^{T=1} \delta_{t} u\left(F\left(k_{t}\right)-k_{t+1}\right)
$$

$$
\begin{aligned}
& 0 \leq k_{t+1} \leq F\left(k_{t}\right), \text { for } 0 \leq t<T \\
& k_{0}, k_{T}>0 \text { given. }
\end{aligned}
$$
conditions

Write $\gamma_{t}=\delta_{t} / \delta_{t-1}$ for $1 \leq t<T$. Then the solution satisfies the first order

$$
\begin{aligned}
& \gamma_{t} F^{\prime}\left(k_{t}\right) u^{\prime}\left(F\left(k_{t}\right)-k_{t+1}\right)=u^{\prime}\left(F\left(k_{t-1}\right)-k_{t}\right), \quad 1 \leq t<T \\
& k_{T}, k_{0}>0 \text { given. }
\end{aligned}
$$

We consider the special case of $F(k)=k^{\alpha}$, and $u(c)=\ln (c)$. In this case, the first line reduces to

$$
\frac{\alpha \gamma_{t} k_{t}^{\alpha-1}}{k_{t}^{\alpha}-k_{t+1}}=\frac{1}{k_{t-1}^{\alpha}-k_{t}}
$$

Writing $\eta_{t}=\alpha \gamma_{t}$, and $z_{t}=k_{t} / k_{t-1}^{\alpha}$ for $1 \leq t<T$, we can rearange terms and rewrite the above as

$$
z_{t}=\frac{\eta_{t}}{1+\eta_{t}-z_{t+1}}
$$

We can solve for the $z_{t}$ as follows. Define $d_{t}$ recursively for $1 \leq t<T$ by

$$
\begin{aligned}
& d_{T}=1 \\
& d_{t}=\eta_{t} d_{t+1}+\left(1-z_{T}\right)
\end{aligned}
$$

So $d_{t}=a_{i}-b_{t} z_{T}$, where $a_{t}=1+\sum_{\tau=t}^{T-1}\left[\prod_{i=t}^{\tau} \eta_{i}\right]$, and $b_{t}=1+\sum_{\tau=t}^{T-2}\left[\prod_{i=t}^{\tau} \eta_{i}\right]$.
Then, for all $t$,

$$
z_{t}=\left(d_{t}-\left(1-z_{T}\right)\right) / d_{t}
$$

To see this, clearly since $d_{T}=1$, the result is true for $t=T$. Suppose the result is true for $t$. Then for $1 \leq t \leq T$,

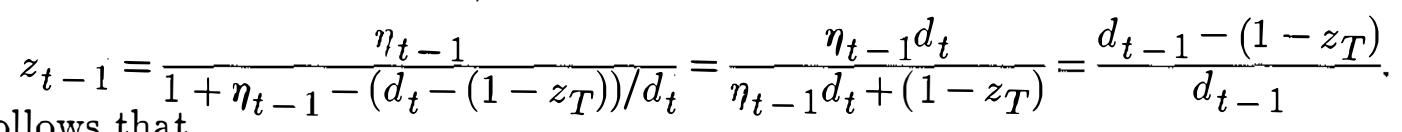

It follows that

$$
z_{t}=\frac{\left(a_{t}-1\right)-\left(b_{t}-1\right) z_{T}}{a_{t}-b_{t} z_{T}}
$$

In the example, $k_{T}=0$. So $z_{T}=0$. To find the $k_{t}$, we first solve for the $z_{t}$, and then solve for the $k_{t}$ the given $k_{0}$ and 


$$
k_{t}=z_{t} k_{t-1}^{\alpha}
$$

We must show that for $j \in K$,

$$
s^{j *}(k) \in \underset{c^{j} \in \mathbb{R}^{+}}{\arg \max } E W_{j}\left(k, e^{*} ; c^{j}\right) .
$$

But since candidates 1 and 2 use the same strategy, $s^{1 *}=s^{2 *}$, then for all $k$, we have

$$
E W_{j}\left(k, e^{*}\right)=\frac{1}{2\left(1-\delta_{j}\right)} \equiv d_{j}>0 .
$$

That is, $E W_{j}\left(k, e^{*}\right)$ is independent of $k$. Thus, $E W_{j}\left(F\left(k_{0}\right)-c^{j}, e^{*}\right)=E W_{j}\left(F\left(k_{0}\right)-\right.$

$$
\begin{aligned}
& \left.s^{-j *}(k), e^{*}\right)=d_{j} \text {. So we can rewrite } \\
& E W_{j}\left(k, e^{*} ; c^{j}\right)= \begin{cases}1+\delta_{j} d_{j} & \text { if } \Phi_{j}\left(k,\left(c^{j}, s^{-j *}(k)\right), \sigma^{*}\right)>0 \\
\delta_{j} d_{j} & \text { if } \Phi_{j}\left(k, c^{j}, s^{-j *}(k)\right), \sigma^{*}<<0 \\
\frac{1}{2}+\delta_{j} d_{j} & \text { if } \Phi_{j}\left(k,\left(c^{j}, s^{-j *}(k)\right), \sigma^{*}\right)=0 .\end{cases}
\end{aligned}
$$

We can rewrite $(5.3)$ as

$$
\mathrm{s}^{j *}(k) \in \underset{c^{j} \in \mathbb{R}_{+}}{\arg \max } \operatorname{sgn}\left\{\Phi_{j}\left(k,\left(c^{j}, s^{-j *}(k)\right), \sigma^{*}\right)\right\}
$$

where $\operatorname{sgn}(x)$ is the sign of $x$. Therefore, in equilibrium, at any capital stock $k, j$ will choose $c^{j}$ to maximize $\operatorname{sgn}\left\{\Phi_{j}\left(k,\left(c^{j}, s^{-j *}(k)\right), \sigma^{*}\right)\right\}$ and will ignore the future. 


\section{REFERENCES}

Alesina, A., "Macroeconomic Policy in a Two-Party System as a Repeated Game," Quarterly Journal of Economics, 102 (1987): 651-678.

Allen, S. D., J. M. Sulock and W. A. Sabo, "The Political Business Cycle: How Significant?" Public Finance Quarterly, 14 (1986): 107-112.

Beck, Nathaniel, "Social Choice and Economic Growth," Public Choice, 33 (1978): 3348.

Boylan, R., "Voting over investment," mimeo, Olin School of Business, Washington University, (1992).

Boylan, R., J. Ledyard, A. Lupia, R. D. McKelvey, and P. C. Ordeshook, "Political Competition in a Model of Economic Growth: Some Experimental Results," in T. Palfrey Ed., Laboratory Research in Political Economy, (Ann Arbor: University of Michigan Press, 1991), pp. 33-67.

Cargill, T. F. and M. M. Hutchinson, "Political Business Cycles with Endogenous Election Timing: Evidence from Japan," Review of Economics and Statistics, Vol 73 (1991): 733-739.

Cass, D., "Optimum Growth in an Aggregative Model of Capital Accumulation," Review of Economic Studies, 32 (1965): 233-240.

Davidson, L., M. Fratianni, and J. von Hagen, "Testing for Political Business Cycles," Journal of Policy Modeling, 12 (1990): 35-59.

Demange, G., "A Limit Theorem on the Minmax Set," Journal of Mathematical Economics, 9 (1982): 145-164.

Findlay, David W. "The Political Business Cycle and Republican Administrations: An Empirical Investigation," Public Finance Quarterly, 12 (1990): 328-338.

Golden, D., and J. Poterba, "The Price of Popularity: The Political Business Cycle Reexamined," American Journal of Political Science, 24 (1980): 696-714.

Grandmont, J. M., "Intermediate Preferences," Econometrica, 46 (1978): 317-330.

Harris, M., Dynamic Economic Analysis, (New York: Oxford University Press, 1987)

Hibbs, D. A., Jr., "Political Parties and Macroeconomic Policy," American Political Science Review, 71 (1977): 146-187.

Keil, M. W. "Is the Political Business Cycle Really Dead?," Southern Economic Journal, 55 (1988): 86-99.

Koopmans, T., "On the Concept of Optimal Economic Growth," The Econometric Approach to Development Planning, (Chicago: Rand-McNally, 1965).

Kramer, G. H., "Sophisticated Voting Over Multidimensional Choice Spaces," Journal of Mathematical Sociology, 2 (1972):165-180.

Kramer, G. H., "Some Extensions of a Dynamical Model of Electoral Competition," mimeo, (1977).

Lazo, J. K., G. H. McClelland, and W. D. Schulze, "What is the Future Worth: An 
Experimental Examination of Rates of Time Preference," mimeo, Department of Economics, University of Colorado, Boulder, (October, 1992).

McCallum, B., "The Political Business Cycle: An Empirical Test," Southern Economic Journal, 44 (1978): 504-515.

McKelvey, R. D., and N. Schofield, "Generalized Symmetry Conditions at a Core Point," Econometrica, 55 (1987): 923-933.

Nordhaus, W. D., "The Political Business Cycle," Review of Economic Studies, 42 (1975): 169-190.

Paldam, M. "Is There an Election Cycle? A Comparative Study of National Accounts," Scandinavian Journal of Economics, Vol 81 (1979): 323-342.

Plott, C. R., "A Notion of Equilibrium and its Possibility Under Majority Rule," American Economic Review, 57 (1967): 787-806.

Ramsey, F., "A Mathematical Theory of Saving," Economic Journal, 38 (1928): 543559.

Rogoff, K., "Equilibrium Political Budget Cycles," American Economic Review, 80 (1990): 21-36.

Rogoff, K., and A. Sibert, "Elections and Macroeconomic Policy Cycles," Review of Economic Studies, 55 (1988): 1-16.

Soh, B. H. "Political Business Cycles in Industrialized Democratic Countries," KYKLOS, 39 (1986): 31-46.

Solow, Robert M., "A Contribution to the Theory of Economic Growth," Quarterly Journal of Economics, 70 (1956): 65-94. 